Acta Theriologica 44 (3): 283-290, 1999.

PL ISSN 0001-7051

\title{
Intersexual attraction in natal dispersing root voles Microtus oeconomus
}

\author{
Gry GUNDERSEN, Jannecke A. MOE, Harry P. ANDREASSEN*, \\ Rine G. CARLSEN and Hege GUNDERSEN
}

Gundersen G., Moe J. A., Andreassen H. P., Carlsen R. G. and Gundersen H. 1999.
Intersexual attraction in natal dispersing root voles Microtus oeconomus. Acta Theriologica 44: 283-290.

By an enclosure experiment we tested whether natal dispersing root voles Microtus oeconomus (Pallas, 1776) were prevented from colonising already occupied habitat patches or if they were attracted to habitat patches by potential mates. The treatment consisted of manipulating the presence of animals in immigration patches, either with the presence of a solitary sexually mature male or female, whereas empty patches were used as a control. Immigration patches were separated from a patch used for release of a matriline (mother with her newly weaned litter) by a semipermeable fence allowing only interpatch movements of young animals. We predicted that either a social fence would prevent immigration to treatment patches, or that potential mates would attract dispersing individuals. In particular we expected fewer dispersing males to colonise male occupied patches, and fewer dispersing females to colonise female occupied patches due to intrasexual competition, ie an intrasexual social fence. We found that a higher proportion of females settled in male treatment patches than in female patches, whereas male dispersal was unaffected by treatment. Thus, the observed female immigration pattern appeared to be an attraction to patches occupied by the opposite sex. We found no sign that immigration was prevented by a social fence.

Department of Biology, Division of Zoology, University of Oslo, P.O. Box 1050, Blindern, N-0316 Oslo, Norway, e-mail: harry.andreassen@bio.uio.no

Key words: Microtus oeconomus, conspecific attraction, dispersal, social fence hypothesis, ontogenetic-switch-hypothesis

\section{Introduction}

Dispersal as a demographic parameter may affect the size of populations (eg Stenseth 1983, Hastings 1990), and it is a key parameter in spatially structured population models, eg metapopulation dynamics (Ims and Yoccoz 1997). However, the role of dispersal in population dynamics is difficult to grasp without an understanding of the mechanisms triggering or preventing dispersal. In the last decades, small mammals have been extensively used as model organisms in studies of dispersal (Stenseth and Lidicker 1992), which have resulted in the identification of a variety of proximate factors causing dispersal. To a large extent, the proximate causes for dispersal have been connected to the natal environment, such as

\footnotetext{
* Corresponding author
} 
maternal condition (Bondrup-Nielsen 1993), litter characteristics (Ims 1987, 1989, 1990, Jacquot and Vessey 1995) and changes in population density or composition of the kin group (Christian 1970, Lidicker 1975, Bekoff 1977, Krebs 1978, Hestbeck 1982, McShea 1990, Wolff 1992, 1993, 1994, Bollinger et al. 1993, McGuire et al. 1993).

All studies mentioned above have been designed to study the mechanisms which repel individuals from their natal area, whereas the motivating mechanisms which may attract individuals to particular areas, and their success of settlement have not been investigated. However, habitat choice and the ability to settle down in a novel area are important aspects for the understanding of population development (see Smith and Peacock 1990, Reed and Dobson 1993). Thus, it should be essential to unravel the behavioural mechanisms involved both in the emigration as well as in the immigration processes of dispersal (Ims and Yoccoz 1997).

We designed an experiment where root voles Microtus oeconomus (Pallas, 1776) were given the option to colonise empty habitat patches (controls), or habitat patches occupied either by a sexually mature female or male (treatments). This experiment was done to test whether already occupied patches acted to prevent (eg as a social fence, Hestbeck 1982), or attract (eg to maximise reproduction, Dingle 1972) dispersing individuals. We chose sexually mature animals as the experimental unit because they are most prone to show aggressive behaviour and exclude intruders, eg function as a social fence, or become potential mates.

We made the following predictions: (1) Given that young voles are attracted to potential mates we predicted that dispersing voles would immigrate more often into patches containing opposite-sex individuals compared to empty (ie control) patches. (2) If dispersing voles were avoiding resource or reproductive competition (see eg Dobson 1982, Pusey 1987), they would settle more often in empty patches compared to patches with same-sex individuals, ie reflecting the effect of an intrasexual social fence.

\section{Material and methods}

\section{Origin of the experimental animals}

Animals used in the present study were laboratory raised root voles originating from Valdres in the southern part of Norway (see Ims et al. 1993, Ims 1997). To randomize between-litter variation (eg genetic variation) and to standardize litter characteristics between treatments, eg litter size and sex ratio, we attempted to cross-foster most of the litters (ie exchanging parents for the whole litter) at an age of 7 days \pm 2 days. Twenty-eight litters were successfully cross-fostered. To increase the sample size, 18 additional litters (not cross-fostered) were included to make a total of 46 litters. Cross-fostered and not cross-fostered litters were randomly allocated to treatments. The average litter size and sex ratio (number of females / litter size) was $5.30(\mathrm{SE}=0.18)$ and $0.45(\mathrm{SE}=0.03)$, respectively.

\section{Experimental procedure}

This experiment was conducted in six $50 \times 16.7 \mathrm{~m}^{2}$ "vole proof" enclosures at Evenstad Research Station, SE Norway (Hedmark), between July 1 and December 18, 1995. The whole study area was surrounded by a $1.5 \mathrm{~m}$ high chicken wire fence to prevent mammalian predation. 


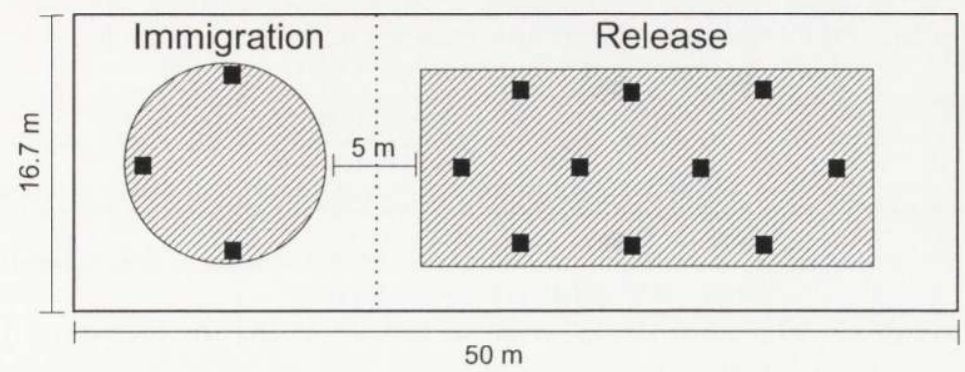

Fig. 1. One of the experimental enclosures with the release and immigration patches (hatched), semipermeable fence (dotted line) and position of live traps (black squares).

Within each of the six enclosures we established two habitable meadow patches embedded in a matrix where the vegetation was removed completely by herbiciding (Fig. 1). These two patches were separated by $5 \mathrm{~m}$ and a semipermeable barrier, made out of chicken wire fence (mesh size: $11 \mathrm{~mm}$ ), which prevented interpatch movement of animals larger than $30 \mathrm{~g}$. One patch $(28 \mathrm{~m} \times 13 \mathrm{~m})$, hereafter termed the release patch, was colonised at the onset of each trial by releasing a root vole female and her newly weaned litter (18 d old). The other habitat patch, termed treatment patch, was circular (50 $\mathrm{m}^{2}$; ca. the size of a female root vole core area (Andreassen et al. 1998) and was used for the experimental manipulation. In the treatment patch we released either a sexually mature female which had previously given birth to one litter, a sexually mature male (ie scrotal), or left the patch empty. Hence, there were 3 treatment levels, hereby called female, male and control treatment, respectively. A total of 9 different females were used to colonise female patches with a mean weight of $43.6 \mathrm{~g}$ ( $\mathrm{SE}=$ 0.9 ) and a total of 15 different males were used to colonise male patches with a mean weight of $51.6 \mathrm{~g}$ $(\mathrm{SE}=1.4)$. Thus, the semipermeable fence was a barrier for all treatment animals, except for the young animals which on average weighed $13.1 \mathrm{~g}(\mathrm{SE}=0.3)$ and $13.8 \mathrm{~g}(\mathrm{SE}=0.3)$, females and males respectively, at the time of release.

The release patch was empty of other voles. Before release, weight and sex were recorded and each individual was uniquely marked by toe clipping. Each trial lasted for 16 days whereafter the surviving animals were removed by live trapping (Ugglan multiple capture traps) which lasted for two days. Moreover, we also performed live trapping sessions, which lasted for 24 hours ( 2 trap checks), 4 and 9 days after release. All traps were baited with potatoes and whole grained oats and were checked twice daily (see Fig. 1 for trap location). For each captured individual we recorded toe code, sex, weight and trap station. At the end of a trial the animals were killed by cervical dislocation and autopsied (see Gundersen and Andreassen (1998) for ethical considerations). Pregnancy and presence of tubuli epididymus were recorded for females and males, respectively, and have here been used to define sexual maturation.

We performed 6 experimental trials (one in each enclosure) during 9 consecutive periods. For each period the location of the three treatment levels were randomized between the six enclosures, with the restriction that the subsequent treatments in each enclosure should differ. Lack of appropriate animals forced us to exclude female treatment the last 3 periods. A total of 9,18 and 19 trials were performed for female, male and control treatments, respectively.

\section{Analyses}

Natal dispersal in voles appears shortly after weaning (Boonstra et al. 1987, Ims 1990, Lambin 1994). The 16 day long period of each trial should therefore suffice to observe natal dispersal and settlement triggered by factors in the life history of the individuals. We defined dispersers as young animals recaptured in the immigration patch at the end of a trial, assuming that they had succeeded in settling down in the immigration patches. 
Table 1. Description of the litter specific responses analysed in the present study.

\begin{tabular}{lc}
\hline Response & \multicolumn{1}{c}{ Description } \\
\hline Survival & $\begin{array}{c}\text { The proportion of same sex individuals in a litter released that were } \\
\text { recaptured } \\
\text { The proportion of same sex individuals in a litter recaptured in the } \\
\text { immigration patch at the end of a trial }\end{array}$ \\
Female sexual maturity & $\begin{array}{c}\text { The proportion of pregnant females among the littermates (from autopsy } \\
\text { data) } \\
\text { Male sexual maturity }\end{array}$ \\
$\begin{array}{c}\text { The proportion of males with visible tubuli epididymus among the littermates } \\
\text { (from autopsy data) } \\
\text { The growth in grams (averaged over same-sex individuals in a litter) from } \\
\text { release to recapture }\end{array}$
\end{tabular}

The binomial responses; like survival, dispersal, and sexual maturation (see Table 1 for description of the responses), were analysed by logistic regression, whereas growth rate of young was analysed by the use of ANCOVA. All analyses were performed for the sexes in each litter separately, (ie proportion of females/males in the litter in logistic regression, and mean for females/males in the litter in ANCOVA). Preliminary analyses showed only minor $(p>0.10)$ effects of possible covariables, such as litter characteristics (litter size, sex ratio and mean body mass at time of release) and maternal characteristics (body mass and survival), and were therefore excluded from further analysis. However, we included period as a covariable in the analyses of treatment effects, whenever it was significant $(p<0.05)$.

\section{Results}

The proportion of individuals in litters that survived the 16 days of the experimental trial averaged $0.81(\mathrm{SE}=0.03)$ and was not significantly affected by treatment (Table 2). There was significant treatment effects on female dispersal, but not on male dispersal (Table 2). A higher proportion of females in a litter settled in patches occupied by a sexually mature male than in patches occupied by a female (Fig. 2). The proportion of sexually mature females in a litter was largest in male

Table 2. Statistics for sex specific test for treatment effects in logistic models. See Table 1 for a description of responses.

\begin{tabular}{llcr}
\hline Response & \multicolumn{1}{c}{ Sex } & $\chi^{2}(\mathrm{df}=2)$ & $p$ \\
\hline Survival & Females & 2.02 & 0.364 \\
& Males & 5.11 & 0.078 \\
Dispersal & Females & 9.95 & 0.007 \\
& Males & 2.24 & 0.326 \\
Sexual maturation & Females & 25.92 & $<0.001$ \\
& Males & 2.27 & 0.322 \\
\hline
\end{tabular}



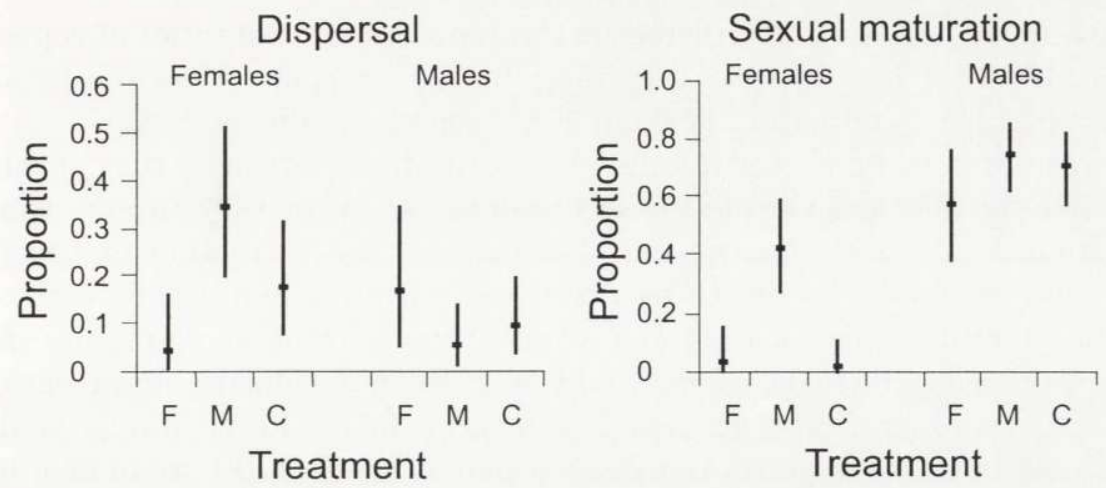

Fig. 2. Proportion $( \pm 2 \times \mathrm{SE})$ of females and males in a litter that dispersed and attained sexual maturation during a trial in the 3 treatments $(\mathrm{F}$ - female patches, $\mathrm{M}$ - male patches, $\mathrm{C}$ - control patches). See Table 1 for a description of variables.

treatment compared to the other two treatment levels, whereas we found no effect of treatment on male sexual maturation (Table 2, Fig. 2).

The mean body growth rate of individuals in a litter decreased throughout the season both among females $\left(\beta=-0.97, \mathrm{SE}=0.31, F_{1,38}=9.81, p=0.003\right)$ and among males $\left(\beta=-1.38, \mathrm{SE}=0.24, F_{1,42}=34.66 p<0.001\right)$. The mean body growth rate of males in a litter was not affected by the treatment $\left(F_{2,37}<1,69, p>\right.$ 0.120 ), but females grew faster in male treatment plots compared to the other two treatment plots $\left(F_{2,33}=3.29, p=0.049\right.$; period as a covariat: $F_{1,33}=12.95, p=$ 0.001 ). Increased growth rate among females was probably due to a higher pregnancy rate in male treatment, and using the proportion of pregnant females in the litter as a cofactor $\left(F_{1,32}=7.42, p=0.010\right)$ removed treatment effects of female growth $\left(F_{2,32}=0.61, p=0.551\right)$.

\section{Discussion}

We have presented the results of an experiment in which we used root vole litters as the observational unit to test whether conspecifics in neighbouring patches inhibited or promoted natal dispersal in root voles. We found that a higher proportion of females immigrated to male patches than to female patches, whereas males were unaffected by treatment. Consequently, our results show a different dispersal pattern for the sexes. However, because dispersal of females did not differ between female and control treatment (see Fig. 2), the dispersal pattern appeared not to be caused by an intrasexual defence of habitat patches. On the contrary, our results suggest intersexual attraction to be a mechanism of habitat choice and settlement in young female root voles. The higher proportion of pregnant females in male treatments show that female dispersal events were not only occasionally sallies, but resulted in mating and probably settlement. The intersexual attraction 
observed in the present study increased the reproductive potential of reproducing females as would be expected according to the ontogenetic-switch-hypotheses (Dingle 1972, Holekamp and Sherman 1989, see also Lidicker 1985).

Our results must be viewed in light of the unnatural setting of the experimental design. The factors observed to affect dispersal did so in very simple, controlled circumstances. Even though we found an intersexual attraction in the present setting, this might not come to be expressed within a population with a more complicated level of organisation and a multitude of influencing factors. A social fence mechanism (Hestbeck 1982) could be a factor inhibiting immigration in a population were a social group acts as the social fence. For instance, males and females may be more disposed to defend a patch if they had a mate or a litter to defend. The absence of intrasexual defence of immigration patches was anyway quite surprising as the immigration patches were small, about the size of a female root vole core area (Andreassen et al. 1997), and thus with no surplus of resources.

Furthermore, dispersal distance was limited in the enclosures. It may even be argued that the short distance between patches could hardly be called dispersal. However, an interpatch distance of $4 \mathrm{~m}$ limit mature male root vole movement in unfamiliar areas (Andreassen et al. 1996), and interpatch distances between 4 and $9 \mathrm{~m}$ hinder female root voles to include multiple habitat fragments within their home range (Berg 1995). Our discrete habitat patches separated by $5 \mathrm{~m}$ in addition to the semipermeable fence should therefore represent a situation where young animals that settle in the immigration patches no longer have any contact with the natal area (dispersal sensu Stenseth and Lidicker 1992). Due to the short distance between release and immigration patches $(5 \mathrm{~m})$, however, young animals released might have been attracted to disperse because they smelled or heard animals in the immigration patches. However, during the phase of dispersal individuals finally choose a habitat patch according to some cues. Such cues might be the presence of conspecifics (Stamps 1988), or intersexual conspecifics as suggested in the present study.

We found a higher proportion of females to be pregnant in male treatment compared to female and control patches. The lack of an experienced mate for the young females in the release patch may have forced females to disperse more than would be expected in the presence of an adult male. Young females in control and female treatments could only have mated with their brothers which were not sexually mature at the time of release, although a high proportion of the young males were sexually mature at removal. Thus, low pregnancy rates in control and female treatments could have been due to the absence of large, experienced males. However, low pregnancy rates may also have been an avoidance of kin mating. Santos et al. (1995) did show some degree of inbreeding depression in laboratory experiments on the same strain of root voles as the one used in this study.

Although the experimental design may limit the generality of our results, it still gives a novel insight to microtine natal dispersal. Possible proximate factors for explaining natal dispersal have previously been examined from the perspective of 
the natal environment (eg Ims 1987, 1989, 1990, McShea 1990, Wolff 1992, 1993, 1994, Bondrup-Nielsen 1993, Jacquot and Vessey 1995). These studies have focused on mechanisms that stimulate voles to leave their natal area, rather than on what may attract them to a new area. As far as we know, the present study is the first in the microtine literature suggesting that dispersal might appear as an attraction towards voles of the opposite sex in the neighbourhood.

In conclusion, we were not able to confirm that root vole colonisation is prevented by conspecifics. Our results instead suggest that in the absence of potential mates in the natal area, there may be an intersexual attraction mechanism of natal dispersal in root voles as an adaptation to accelerate mating in females. Thus, with the constraints of the present experimental setting, we found natal dispersal to be in accordance with the ontogenetic switch hypothesis (Dingle 1972, Holekamp and Sherman 1986). In accordance with previous studies (Ims 1989) we found the ontogenetic switch to be more flexible in females than in males.

Acknowledgements: This study was supported financially by the Nansen endowment foundation. We are grateful for all help J. Aars gave us in connection with the field work, and to R. A. Ims, J. Aars, A. Kielland, L. Hansson and J. Wolff for critical remarks to the manuscript.

\section{References}

Andreassen H. P., Herzberg K. and Ims R. A. 1998. Space-use responses to habitat fragmentation and connectivity in the root vole Microtus oeconomus. Ecology 79: 1223-1235.

Andreassen H. P., Ims R. A. and Steinset O. K. 1996. Discontinuous habitat corridors: effects on male root vole movements. Journal of Applied Ecology 33: 555-560.

Bekoff M. 1977. Mammalian dispersal and the ontogeny of individual phenotypes. The American Naturalist 111: 715-732.

Berg K. W. 1995. Space use responses of root voles (Microtus oeconomus) to a habitat fragmentation gradient. Cand. Scient. thesis, University of Oslo: 1-51.

Bollinger E. K., Harper S. J. and Barrett G. W. 1993. Inbreeding avoidance increases dispersal movements of the meadow vole. Ecology 74: 1153-1156.

Bondrup-Nielsen S. 1993. Early malnutrition increases emigration of adult female meadow voles, Microtus pennsylvanicus. Oikos 63: 317-320.

Boonstra R., Krebs C. J., Gaines M. S., Johnson M. L. and Craine I. T. M. 1987. Natal philopatry and breeding systems in voles (Microtus spp.). Journal of Animal Ecology 56: 655-673.

Christian J. J. 1970. Social subordination, population density, and mammalian evolution. Science 168: 84-90.

Dingle H. 1972. Migration strategies of insects. Science 175: 1327-1335.

Dobson F. S. 1982. Competition for mates and predominant juvenile male dispersal in mammals. Animal Behaviour 30: 1183-1192.

Gundersen G. and Andreassen H. P. 1998. Causes and consequences of natal dispersal in root voles, Microtus oeconomus. Animal Behaviour 56: 1355-1367.

Hastings A. 1990. Spatial heterogeneity and ecological models. Ecology 71: 421-423.

Hestbeck J. 1982. Population regulation of cyclic small mammals: the social fence hypothesis. Oikos 39: 157-163.

Holekamp K. E. and Sherman P. W. 1989. Why male ground squirrels disperse. American Scientist 77: 232-238.

Ims R. A. 1987. Responses in the spatial organization and behavior to manipulations of the food resource in the vole Clethrionomys rufocanus. Journal of Animal Ecology 56: 485-596. 
Ims R. A. 1989. Kinship and origin effects on dispersal and space sharing in Clethrionomys rufocanus. Ecology 70: 607-616.

Ims R. A. 1990. Determinants of natal dispersal and space use in the gray-sided vole, Clethrionomys rufocanus: a combined laboratory and field experiment. Oikos 57: 106-113.

Ims R. A., Rolstad J. and Wegge P. 1993. Predicting space use responses to habitat fragmentation: Can voles Microtus oeconomus serve as an experimental model system (EMS) for cappercaillie grouse Tetrao urogallus in boreal forest? Biological Conservation 63: 261-268.

Ims R. A. and Yoccoz N. G. 1997. Studying transfer processes in metapopulations: Emigration, migration, and colonization. [In: Metapopulation biology: Ecology, genetics, and evolution. I. A. Hanski and M. E. Gilpin, eds]. Academic Press, London: 247-265.

Ims R. A. 1997. Determinants of geographic variation in growth and reproductive traits in the root vole. Ecology 78: 461-470.

Jacquot J. J. and Vessey S. H. 1995. Influence of the natal environment on dispersal of white-footed mice. Behavioural Ecology and Sociobiology 37: 407-412.

Krebs C. J. 1978. A review of the Chitty hypothesis of population regulation. Canadian Journal of Zoology 56: 2463-2480.

Lambin X. 1994. Natal philopatry, competition for resources and inbreeding avoidance in Townsend's voles (Microtus townsendii). Ecology 75: 224-235.

Lidicker W. Z. 1975. The role of dispersal in the demography of small mammals. [In: Small Mammals: Their productivity and population dynamics. F. B. Golley, K. Petrusewicz and L. Ryszkowski, eds]. Cambridge University Press, Cambridge: 103-128.

Lidicker W. Z. 1985. Dispersal. The American Society of Mammalogists, Special publication 8: 420- 454.

McGuire B., Getz L. L., Hoffman J. E., Pizzuto T. and Frase B. 1993. Natal dispersal and philopatry in prairie voles (Microtus ochrogaster) in relation to population density, season, and natal environment. Behavioural Ecology and Sociobiology 32: 293-302.

McShea W. J. 1990. Social tolerance and proximate mechanisms of dispersal among winter groups of meadow voles, Microtus pennsylvanicus. Animal Behaviour 39: 3436-351.

Pusey A. E. 1987. Sex-biased dispersal and inbreeding avoidance in birds and mammals. Trends in Ecology and Evolution 2: 295-299.

Reed J. M. and Dobson A. P. 1993. Behavioral constraints and conservation biology: conspecific attraction and recruitment. Trends in Ecology and Evolution 8: 253-256.

Santos E. M. dos, Andreassen H. P. and Ims R. A. 1995. Differential inbreeding tolerance in two geographically distinct strains of root voles Microtus oeconomus. Ecography 18: 238-247.

Smith A. T. and Peacock M. M. 1990. Conspecific attraction and the determination of metapopulation colonisation rates. Conservation Biology 4: 320-323.

Stamps J. A. 1988. Conspecific attraction and aggregation in territorial species. The American Naturalist 131: 329-347.

Stenseth N. C. 1983. Causes and consequences of dispersal in small mammals. [In: The ecology of animal movement. I. R. Swingland and P. J. Greenwood, eds]. Clarendon Press, Oxford: 63-101.

Stenseth N. C. and Lidicker W. Z. 1992. Animal dispersal: Small mammals as a model. Chapman and Hall, London: 1-365.

Wolff J. O. 1992. Parents suppress reproduction and stimulate dispersal in opposite-sex juvenile white-footed mice. Nature 359: 409-410.

Wolff J. O. 1993. What is the role of adults in mammalian juvenile dispersal? Oikos 68: 173-176.

Wolff J. O. 1994. More on juvenile dispersal in mammals. Oikos 71: 349-352.

Received 14 April 1997, revised 3 March 1999, accepted 20 May 1999. 